\title{
International Perspectives on ePortfolios in Higher Education: Case Studies from Asia, North America and Europe
}

\author{
https://doi.org/10.3991/ijet.v14i21.11048 \\ Monika Ciesielkiewicz $(\bowtie)$ \\ Villanueva-Complutense University of Madrid, Costa Brava, Spain \\ mciesielkiewicz@villanueva.edu \\ William Wisser \\ Harvard University, Boston, USA \\ Diane Rozells \\ Sookmyung Women's University, Seoul, South Korea
}

\begin{abstract}
The authors of this paper explore case studies from three different universities: Harvard University, Sookmyung Women's University, and Villanueva-Complutense University of Madrid. Although each case is in a different country on three different continents, what they have in common is that they all implemented ePortfolios at the course level within a Master of Education Program. ePortfolios are dynamic tools that can be used for many functions, which can be sorted into three categories: learning, evaluation, and career development. This paper analyzes the success factors of the three ePortfolio use cases as well as the challenges that can be considered generalizable and others that are more culturally specific. The exploration of different perspectives can help to develop a common understanding of the uses, benefits, and potential of ePortfolios in higher education.
\end{abstract}

Keywords-ePortfolio, Higher Education, case studies, ICT, International Education

\section{Introduction}

In this information age, where technology exerts an ever-increasing influence in educational settings across the globe, ePortfolios are steadily replacing traditional paper-based portfolios in higher education programs as tools for reflection, professional development and assessment [1], [10], [22], [27],[32], [33]. Eynon and Gambino (2017) [12] define student ePortfolios as "web-based, student-generated collections of learning artifacts (papers, multimedia projects, speeches, images, etc.) and related reflections, focused on learning and growth." (p.1) This electronic document can include both experiences and skills acquired as part of and beyond the educational settings [7], [10]. The digital version holds many advantages, such as accessibility, 
ease of duplication and storage, potential for continuous updates, and ability to include hyperlinks, audio and video data that enable a more dynamic presentation of the contents ([4], [15], [17], [19], [23]. Furthermore, students benefit from greater opportunities for reflection, owing to increased potential for connections between different media types, standards and artifacts [15], [19], as well as from having an increased knowledge of technology applications [14], [19], [30].

According to Bolliger \& Shepherd (2010) [3] ePortfolios are extensively used in higher education as a tool to help students develop critical thinking and problemsolving skills. As noted by Woodyard (2016) [34], there has been a steady increase in implementation of ePortfolios in higher education. Moreover, the Association of American Colleges \& Universities added ePortfolios to the list of eleven high-impact practices (HIPs), which are defined as those that have the most impact on student learning and engagement [31]. However, ePortfolio implementation requires much more than just an effective platform [12]. Therefore, much research has been done on the implementation of ePortfolios by administrators and faculty [24], [28], [29]. Nevertheless, very little is known about cultural differences in ePortfolio implementation in different countries and whether or how these cultural differences affect the process and outcomes of ePortfolio implementation. Cronjé's (2006) [9] study explored cultural differences in ePortfolio implementation in South Africa and Sudan, and Ellis, Roehrer and Kelder (2013) [11] analyzed key differences between Australian and Chinese students. Woodyard (2016) [34] researched culturally based learning preferences in an ePortfolio project while Bilsland (2013) [2] proposed using ePortfolios in Transnational Asian Campuses in order to assist their offshore students in applying their learning to their local culture, setting, and context. According to Gómez-Rey, Barbera, and Fernández-Navarro (2016) [13], it is fundamental to identify and incorporate critical learning factors for each culture in order to successfully implement online learning environments. They also suggest that instructors and instructional designers take into account cultural factors in education and that they offer culturally adaptive and sensitive instruction. Additionally, Woodyard (2016) [34] believes that it would be useful to explore how assessing and applying students' culturally based learning preferences could facilitate the implementation of educational ePortfolios.

This study, which extends the comparisons across three continents, explores three cases of ePortfolio implementation in MA Education programs in the United States, Spain and South Korea to uncover common features in ePortfolio implementation across the globe, as well as features which are more culture-specific, using Hofstede's Cultural Dimensions theory [16] as a means for better understanding the cultural differences between these countries. 


\section{Harvard Graduate School of Education (Cambridge, MA, USA)}

\subsection{Context}

The Teaching and Learning Lab (TLL) is a design and development organization dedicated to advancing strategic and innovative initiatives related to teaching and learning at the Harvard Graduate School of Education (HGSE). Each semester the TLL offers a graduate-level course titled "T127: The Teaching and Learning Lab Practicum." The course is based on a cognitive apprenticeship model where students apply course principles related to the design and development of learning experiences to actual ongoing projects within the TLL. Students are embedded in active project teams that may include HGSE faculty members, administrators, and TLL staff members and produce real-world work products that they display on their professional electronic portfolios (ePortfolio).

\subsection{Aims and outcomes}

A major focus of T-127 is to provide students valuable professional experience as learning designers or learning technologists while they grapple with abstract researchbased concepts in the course work. But simply completing the work is only part of the value of a professional experience; students also need to showcase their accomplishments to prospective employers and peers and reflect on their development. ePortfolios are used as the vehicle to accomplish this goal.

ePortfolios in T127 are used in three ways [8]. They are:

- An employment portfolio that showcases skill development aimed at demonstrating competency in relevant domains.

- An assessment portfolio that provides evidence to allow evaluators to award credentials of competency or mastery.

- A reflective portfolio that provides the learner with the opportunity to analyze progress toward competency development over time.

The ePortfolio assignment in T127 is intended to be a learning-oriented assessment [5] in that by completing the task students learn more about themselves as learners and construct lasting mental models of the material through reflection and application. The ePortfolios created by students are populated with artifacts (elements of their projects, thoughts on the readings, coursework from other classes that is relevant to the practicum content area, etc.) developed during the practicum. The artifacts are tangible and durable records of accomplishment that can be shown to prospective employers as evidence of skill development and to the instructor of the practicum course as evidence that shows the learner has met the learning outcomes of the course. The ePortfolios are also populated with weekly reflections on the course readings, discussions, or project meetings. A final ePortfolio assignment (part of the capstone project that determines successful completion of the course) is to reflect on the jour- 
ney that is captured in the ePortfolio. Students share their reflection in a brief presentation to peers that includes their decision-making process regarding how they structured and made use of the ePortfolio. The instructor reads each portfolio post and contributes a brief response on a weekly basis.

\subsection{Critical success factors}

A central premise in the design of the ePortfolio assignment in T127 is that students must find value in them. An ePortfolio is only useful if it is used. An important factor drawn from motivation research is that students should feel empowered to make choices regarding how they engage with the course materials and assignments [25] [26].

Student choice and agency is present in the ePortfolio assignment for T127 in several ways. First, students can choose the ePortfolio platform they would like to use, including leveraging an existing portfolio site they have developed for a different purpose. The course instructor provides direction and support for using a particular tool (Pathbrite), but students are able to choose whatever tool they want to use (WordPress, Wix, Google sites, etc.). Second, while students are required to post each week to their portfolio, what they post is up to them. By allowing students the opportunity to reflect on their learning without restrictions, the ePortfolio assignment feels personal and customizable to the student. Finally, students are required to present their ePortfolio and the decisions they made around its use to their peers at the end of the semester. Since the ePortfolio represents their personal journey to mastering professional skills, they are invested in the final product and are excited to showcase their work.

\subsection{Challenges}

There are several challenges in supporting an ePortfolio assignment as a required and regular part of course assessment. First, while providing choice of platform does promote student engagement in the assignment, providing support for multiple platforms can be a challenge. Second, students find the weekly response from the instructor to portfolio posts to be valuable both as input on the direction of their project work and as a signal that their posts are valued. Even though the size of this course is capped at 15 students due to its design as a practicum, responding to each student on a weekly basis can be time consuming. Finally, the use of ePortfolios in this case study is limited to the T127 course. Therefore, the ePortfolio captures only a fraction of each student's "whole digital self" [18]. Integrating the course ePortfolio assignment with program or degree-level portfolios may provide a richer opportunity for student reflection on their development as learners.

\subsection{Cultural aspects of ePortfolio implementation}

People living in the United States score low on Hofstede's power distance index (40) and high on both individualism (91) and masculinity (62) indices. The combina- 
tion of these scores has significant impact on how students craft their ePortfolios. Students in T127 value the open-ended ePortfolio assignment that allows them to choose their own platform and customize it to present a personalized perspective on their work. Students who score low on a power distance index are likely to question the value of an assignment if they do not perceive the relevance of the work to their learning or career development. The ePortfolio assignment in this course reduces this risk while also tapping into U.S. students' individualism by allowing students to have control over what they post on a regular basis.

Students in the T127 course enjoyed having access to each other's portfolios and the portfolios of previous classes. They could use the portfolios of their peers for inspiration in crafting their own. While the evaluation process was not comparative, students who may score high on a masculinity index will value viewing the work of their peers as a gauge for success. The final assignment related to the ePortfolio asks students to describe their ePortfolios to the whole class. Presenting publicly on what usually is considered a space for private reflection provides an added incentive to carefully construct and deliver the message conveyed by the ePortfolio.

Finally, if students had technical difficulties or questions about what should be placed on their ePortfolios they tried to solve them on their own or discussed with their peers rather than asking for help from the instructor. This strategy is reflective of a high score on Hofstede's individualism index.

\section{Villanueva-Complutense University of Madrid, Spain}

\subsection{Context}

Each semester a course called Design and Evaluation of Lesson Units Educational and Technological Research is offered to students of the Master of Education Program at Villanueva-Complutense University. As part of the course, ePortfolios are used as a learning and a reflection tool to prepare student teachers for their Practicum. It covers lesson plan design, using technology in language teaching and learning, materials design for the ESL classroom, as well as assessment. The course is focused on preparing students for a successful teacher training experience.

Students are exposed to a variety of critical theoretical approaches to teaching English as a second language. Students read, reflect on assigned texts, and discuss them in class. Through their ePortfolios, students document their ability to put these theories into practice. They apply their knowledge in a variety of immersive and hands-on learning activities and evidence-based practices. They learn different resources and ICT (Information and Communications Technology) tools and prepare didactic materials for their Practicum experience, which consists of co-teaching classes in a public or private high school during a period of one month.

Students have access to a model ePortfolio created by the instructor where they can find detailed guidelines. Students' ePortfolios mirror the instructor's ePortfolio. They work on their ePortfolios and upload their assignments weekly. They present their 
ePortfolio posts in class and receive constructive feedback from both their peers and instructor.

Additionally, students transform their course portfolio into a career portfolio at the end of the semester by adding their $\mathrm{cv}$, mission statement and selecting those artefacts which they feel best showcase their academic and professional experience.

\subsection{Aims and outcomes}

ePortfolios make visible student learning by helping them make connections and integrate their learning. The ePortfolio is used in this course as: 1) a tool for generating new and deeper learning where the goal is to help students examine and reflect on their learning; 2) a tool for assessment aimed at evaluating student learning; 3) a tool to showcase their achievements to employers where the goal is to create a career ePortfolio that could be used as an enhanced resume with a variety of media.

The ePortfolio serves to support students' abilities to articulate skills and knowledge developed through this course, as well as to apply them in a real-life context, in particular preparation for their Practicum experience. The ePortfolio also serves as a high-impact practice that amplifies the effectiveness of the coursework [12], [20], [21], [31]. It also allows students to make their work visible and public [6]. It showcases the unique professional experience of designing teaching materials and resources that they will use during their teaching training and their future jobs.

Students create a career an ePortfolio by making a copy of their course portfolio and adding their best work, volunteer and work experiences, and providing evidence of their achievements and skills they developed throughout their university career. They are also encouraged to share the link to their career ePortfolio on their LinkedIn account. Spain's youth unemployment rate is $32.7 \%$; therefore, students have to make an extra effort to differentiate themselves in the competitive job market. The ePortfolio can distinguish them in job searches and help them stand out among other job applicants.

\subsection{Critical success factors}

Step-by-step student training, and individual tutorials were considered to be very helpful by the students. Continuous and frequent feedback from peers and the instructor in class while presenting different parts of their portfolio was also very beneficial. It helped with the deadlines, as well.

Clearly transmitting the purpose of the ePortfolio, explaining its benefits to students and discussing how it is personally meaningful to them have been key success factors. Additionally, providing examples of successful ePortfolios created by students has been very useful too.

Students are the owners of their ePorfolios and the instructor is a co-owner. In this way the instructor can be of help whenever there is any technical problem, as well as have the ability to make a copy of the ePortfolios for assessment purposes. The instructor is then removed as co-owner at the end of the semester. Students reported liking this arrangement. 
Students were able to reflect on, plan ahead and prepare for their forthcoming teacher training, as well as create useful resources that they could use in the classrooms. This real-world connection and application are motivating for students and turned out to be one of the highlights of the course.

\subsection{Challenges}

Due to lack of financial support on behalf of the institution, the instructor had to opt for platforms that are free of charge, which usually have certain limitations. In this case, Google Sites was chosen. Google Sites can be a good fit for institutions and programs with low budgets and it has a great advantage of direct integration to other Google applications, as well as control over sharing options. Also, there are many Google Sites tutorials offered on YouTube that are very helpful whenever the instructor or IT services are not available. However, the user interface used by Google Sites is not always as intuitive, user-friendly or customizable as other platforms. It does not offer an intuitive drag-and-drop interface that students are used to. The lack of an autosave feature for students who are used to working with Google Drive caused some frustration at the beginning. Some features took time for students to learn and are not easy to find.

Late submissions may be problematic. Most Master's degree students are employed while they study, and they often use their jobs as an excuse to post late assignments. Spaniards are more relaxed as for time constraints. It is a polychronic culture where time is not linear without a clear beginning and an end. The focus is on "here and now."

Keeping track of students' reflections and assessment of online assignments can be time-consuming; however, this challenge also depends on the size of the group. A baseline technological competence was considered a challenge. Students required more technical support and guidance than expected by the investigator.

\subsection{Cultural aspects of ePortfolio implementation}

Spain is a hierarchical society and scores high (57) on Hofstede's power distance index (PDI). Spanish students who worked with ePortfolios as a part of their coursework expected to be told in detail what to do and they had little self-initiative and creativity. They do not like to be given too much choice and freedom related to assignments, tasks, and projects. They preferred to be be given a structure, with step-bystep explanations, and be guided through the whole process of ePortfolio creation. They prefered to be told what platform to use and were not very proactive. If a question or technical problem arose, they did not find the answers by themselves but rather asked the instructor in class or via email.

As for the individualism vs collectivism dimension (IDV), Spanish students enjoyed both working on their ePortfolio individually as well as in groups with no particular preference. According to Hofstede, Spain scores 51 in this dimension, which is just in the middle. Hence, Spain reflects some aspects of an individualist culture but also some of a collectivist culture. 
Spanish students did not really try to personalize their ePortfolio. Only the main page differed from one student to another. They followed the guidelines and only wanted to meet the requirements and the rubrics for the course. This reflects the fact that in Spain in general, standing out is not valued and competitiveness is not appreciated.

The Spanish score on masculinity vs. femininity dimension (MAS) is 42 , which is considered low. Students are not very competitive and sometimes are even afraid to be rejected by the group if they are the best and stand out too much.

Regarding the uncertainty avoidance index (UAI), Spain's score is very high (86), which is one of the highest scores when compared to all of countries surveyed. This can be clearly seen in students' attitudes towards the ePortfolio assignments. They expected clear structure and well-defined rules. They felt insecure and anxious when those were not provided. The instructor is the authority who sets the rules and the expert who reduces insecurity. They also did not like when changes were introduced during the semester.

Furthermore, Spain is a short-term oriented and normative culture according to Hofstede. Its score in long-term orientation dimension is 48. Spaniards like to live in the moment and look for quick results without delays. It can be observed in students' late submissions of their ePortfolio assignments when completed outside of the classroom. The activities that were completed during class time were better received than those assigned to be done at home which were usually submitted late or at the last moment. A great advantage of electronic portfolios is that you can easily see when an assignment was submitted by a student.

\section{Sookmyung Women's University, Seoul, South Korea}

\subsection{Context}

In the Practicum course, taken by students in their final semester of the MA TESOL program at Sookmyung Women's University in Seoul, ePortfolios are used as a tool for reflection on teacher learning and professional development, as well as for assessment purposes.

Students can choose between doing a Process, Product, or Showcase portfolio [4], [27] whichever is more suited to their professional goals. They can also choose which platform they wish to use develop their ePortfolios (e.g. Wix, Wordpress, foliospaces). Depending on their professional goals and the type of portfolio they choose to make, they select various artifacts and write reflections on each artifact's significance in relation to the overall purposes of their portfolios. These artifacts include the assignments that students have done throughout the semester-long course such as their resume, teaching philosophy, action research report, lesson plans and reflections on classroom teaching, as well as materials they have developed for their teaching class. These artifacts are the product of various drafts submitted throughout the course, improved each time after getting feedback from the professor, such that they are of a high quality by the time they are finally published in the e-portfolios. 
Apart from these required artifacts, other artifacts that are related to the specific goals of their portfolios, together with their corresponding reflections, can also be included. Examples of these are articles they have written that were published in journals or magazines, recommendation letters, photographs and videos of classroom teaching.

The ePortfolios are evaluated according to a rubric that is made available to student teachers from the first day of class, so students are able to assess their own progress as they build their portfolios. On completion of the MA course, all students' ePortfolios are openly accessible on the department's website. In this way, students showcase their work in the Practicum and enable opportunities for others to learn from and dialogue with them.

\subsection{Aims and outcomes}

The Practicum course seeks to form student teachers to be reflective practitioners, and the ePortfolio is one of the tools aimed at fostering continuing reflection on their professional development. It is also a tool for reflective dialogue in the classroom, as students are required to present on the contents of their ePortfolio throughout the semester. The ePortfolio is also meant to be applied to their real contexts as a tool to help them achieve their own professional goals, such as getting a promotion or applying for a job. Finally, it is also a means for developing and showcasing students' computer and web design skills, rendering them more employable and confident in the use of technology in the classroom.

\subsection{Critical success factors}

Students are given the freedom to choose which type of portfolio they would like to make (Product, Process or Showcase Portfolio), depending on their unique professional goals. Consequently, they also choose the kinds of artifacts that would be appropriate, in addition to some which are required by the course itself. This real-world connection and freedom of choice is motivating for students.

Since the contents of students' portfolios have undergone several rounds of revision because of feedback given from the professor throughout the course, the final products that are included in the portfolio are of a much higher quality, which students can feel proud of.

The dynamic format of an ePortfolio enables students to include a greater variety of contents such as videos of classroom teaching and hyperlinks that connect each class' lesson plans, materials, and reflections so that they are easily viewed together. These features enable greater reflection on teaching practice and easier navigation between different parts of the portfolio.

For the majority of students, it is their first time to build their own website and they are very happy with the computer and web design skills they have acquired in the process. The fact that students can choose their own platform enables students who are less familiar and confident in using technology to use platforms that are more basic and easier to use. 
Past students' ePortfolios that are readily accessible online serve as effective models for current students who are developing their portfolios. Such a platform is made possible, thanks to the departmental website which allocates one webpage for this purpose.

\subsection{Challenges}

ePortfolios are currently not a requirement for teaching or education-related job applications in the South Korean context. Thus, apart from being a tool for personal reflection and its use in job applications to international schools or in other countries, there could be limited opportunities for students to use the ePortfolio beyond the purposes of learning and assessment within the Practicum course.

However, owing to the rapidly increasing use of ePortfolios as a viable method to evaluate performance and job suitability in teaching and other education-related contexts, its application to the South Korean context would be expected to increase with time. Thus, our graduates will be at an advantage when this change takes place.

\subsection{Cultural aspects of ePortfolio implementation}

South Koreans score high (85) on Uncertainty Avoidance and very low (29) on Indulgence vs. Restraint in Hofstede's Cultural Dimensions. This combination renders them to be hard workers who have an inner urge to keep themselves busy, and are restrained, preferring to sacrifice their leisure time to achieve their goals. This is consistent with the students' performance in the Practicum course at Sookmyung Women's University. They work hard to create and design their ePortfolios in the same 15week semester that they do their teaching practicum twice a week with undergraduate students at Sookmyung Women's University, as well as attend MA classes two evenings a week. On top of that, almost all students work at their regular jobs in other institutions, either full-time or part-time. Yet, they manage to submit their tasks (lesson plans, teaching philosophy, resume, etc.) punctually throughout the semester, revising each task two or three times after getting feedback from the professor. Their promptness in meeting deadlines could also be due to South Koreans' relatively high score on Power Distance (60), which means they respect the authority the professor has in setting the deadlines and try their best to achieve what is asked of them.

In addition, South Korea is a very collectivist society, scoring a low of 18 on Hofstede's Individualism vs. Collectivism index. Furthermore, its score of 39 on the Masculinity vs. Femininity index means it is a relatively feminine society. These two dimensions can be observed in how the practicum students at Sookmyung Women's University work collaboratively with each other in the creation of artifacts for their portfolios. Team teaching and therefore lesson planning is done in dyads or triads, and students have several opportunities to present the contents of their ePortfolios in class where they receive peer feedback to help them improve on their tasks. Students are also generally agreeable to having their ePortfolios posted on the departmental website for future students to refer to as models, since they have also learnt from referring to the ePortfolios of past students. 
Finally, South Koreans score extremely high (100) on Long Term Orientation, which means that they are very pragmatic, innovative and long-term oriented. This can be seen in the students' readiness to experiment with and persevere in learning new technology when creating their own websites, as well as in their openness to create an ePortfolio even though it is very rarely required by educational institutions in South Korea at present. Interestingly, students' ePortfolios are very varied in appearance and show high evidence of creativity. There is also some variety in the types of artifacts that students include in their portfolios. These appear to be contrary to South Koreans' feminine and collectivist nature according to Hofstede's dimensions, but could be explained by its extremely high score on the Long-Term Orientation index.

\section{Conclusion}

The purposes of the ePortfolio in the context of the class assignment are strikingly similar. All include the purposes of assessment, reflection, and presentation/showcase. The similarities in purposes shows a general awareness of the value of ePortfolios in graduate-level education programs and also allows for better cross-cultural comparisons of their use and acceptance by students.

Regarding success factors, in the U.S. and South Korean cases, the flexibility of platform and types of artifacts to include was perceived as motivating by the students. Furthermore, the South Korean case allowed students the option to choose between doing a Product, Process or Showcase portfolio [4], [27]. The availability of choice promoted a personal connection and a sense of ownership to the resulting website. In the Spanish case, the students followed the instructor's guidelines related to the platform and the type of artifacts included, and the instructor used direct classroom instruction to help students understand the value that an ePortfolio can have to their academic and professional careers. While the U.S. and Spain contexts differ on Hofstede's index of individualism and power distance, South Korea and Spain are much more similar on those scales. However, there appears to be a discrepancy in the South Korean case due to the instructor's preference of empowering students through allowing students greater freedom of choice.

The difference in scores on Hofstede's index related to long-term orientation between Spain and South Korea may help explain the difference in approach taken by the Spanish and South Korean students towards the ePortfolios. In the case of South Korea, students diligently learned new technologies, refined their artifacts, and invested time and energy in presenting a formal perspective on themselves as emerging professionals. The Spanish students, on the other hand, met the assignment criteria by following explicit directions and completing the assigned work close to the submission deadline.

The Spanish and U.S. portfolios include works in progress, while the portfolios from the South Korea case are intended to showcase only refined work products. Interestingly, in both the U.S. and South Korean cases, a public display of the ePortfolios by the students was a requirement. While U.S. and South Korean students differ 
on Hofstede's masculinity index, requiring display of ePortfolios may increase student attention to the format and content of the website.

While the ePortfolio assignments in the three different contexts were similar, the student approach to using the ePortfolios and how their perception of value differed. While the U.S. and Spanish students hewed closely to Hofstede's cultural dimensions indices, the South Korean students displayed behaviors that are less closely linked to those measurements. The very high score of South Koreans on the long-term orientation index coupled with the design of the ePortfolio assignment may help explain this occurrence.

\section{References}

Barrett, H. C. (2007). Researching Electronic Portfolios and Learner Engagement: The REFLECT Initiative. Journal of Adolescent \& Adult Literacy, 50(6), 436-449. https://doi. org/10.1598/JAAL.50.6.2

[2] Bilsland, C. (2013). Using Eportfolios in Transnational Asian Campuses. In Proceedings of the International Conference on Managing the Asian Century (pp. 23-30). Springer, Singapore. https://doi.org/10.1007/978-981-4560-61-0 3

[3] Bolliger, D. U., \& Shepherd, C. E. (2010). Student perceptions of ePortfolio integration in online courses. Distance Education, 31(3), 295-314. https://doi.org/10.1080/01587919.201 $\underline{0.513955}$

[4] Bullock, A. \& Hawk, P. (2009). Developing a teaching portfolio ( $3^{\text {rd }}$ edition). Upper Saddle River, NJ: Pearson Education.

[5] Carless, D. (2015). Exploring learning-oriented assessment processes. Higher Education, 69(6), 963-976. https://doi.org/10.1007/s10734-014-9816-z

[6] Ciesielkiewicz, M., \& Coca, D. M. (2013). The electronic language portfolio as a tool for lifelong learning. In Conference proceedings. ICT for language learning (pp. 464-467). libreriauniversitaria. it Edizioni.

[7] Ciesielkiewicz, M. (2019). Education for employability: the ePortfolio from school principals' perspective. On the Horizon, 27(1), 46-56. https://doi.org/10.1108/OTH-01-2019-000 1

[8] Cleveland, R.E. (2018) Using digital portfolios in reflection, assessment, and employment. Tech Trends, Vol. 62(3), pp. 276-285. https://doi.org/10.1007/s11528-018-0262-0

[9] Cronjé, J. C. (2006, July). E-portfolios and cross-cultural assessment. In Sixth IEEE International Conference on Advanced Learning Technologies (ICALT'06) (pp. 494-496). IEEE. https://doi.org/10.1109/ICALT.2006.1652483

[10] Dorninger, C., \& Schrack, C. (2008). Future learning strategy and ePortfolios in education. International Journal of Emerging Technologies in Learning (iJET), 4 (1), 11-14.

[11] Ellis, L., Roehrer, E., \& Kelder, J. A. (2013). The place of surprising results' in research into an assessment design: using portfolios for evidence of individual contribution to group work. In International Conference on Education and New Learning Technologies (Edulearn 2013) (Vol. 1, pp. 6286-6291). http://library.iated.org/view/ELLIS2013PLA

[12] Eynon, B., \& Gambino, L. (2017). High-Impact ePortfolio Practice: A Catalyst for Student, Faculty, and Institutional Learning. Sterling, Virginia: Stylus.

Gómez-Rey, P., Barbera, E., \& Fernández-Navarro, F. (2016). The impact of cultural dimensions on online learning. Journal of Educational Technology \& Society, 19(4), 225238. http://hdl.handle.net/10609/70692 
[14] Hanum, S. R., Che-Ani, A. I., Johar, S., Ismail, K., \& Razak, M. Z. A. (2016). ePortfolio: A descriptive survey for contents and challenges. International Journal of Emerging Technologies in Learning (iJET), 11(01), 4-10. https://doi.org/10.3991/ijet.v11i01.4900

[15] Hewett, S. M. (2004). Electronic portfolios: Improving instructional practices. TechTrends, 48(5), 24-28. https://doi.org/10.1007/BF02763526

[16] Hofstede, G., Hofstede, G. J., \& Minkov, M. (2010). Cultures and organizations: Software of the mind (3rd ed.). New York, NY: McGraw-Hill.

[17] Johnson, R. S., Mims-Cox, J. S., \& Doyle-Nichols, A. (2010). Developing portfolios in education: A guide to reflection, inquiry and assessment. Los Angeles: Sage. https://doi. org $/ 10.4135 / 9781483349398$

[18] Kehoe, A., \& Goudzwaard, M. (2015). ePortfolios, badges, and the whole digital self: How evidence-based learning pedagogies and technologies can support integrative learning and identity development. Theory into Practice, 54(4), 343-351. https://doi.org/10.1080/0040 $\underline{5841.2015 .1077628}$

[19] Koraneekij, P., \& Khlaisang, J. (2019). Students' Beliefs Regarding the Use of E-portfolio to Enhance Cognitive Skills in a Blended Learning Environment. International Journal of Emerging Technologies in Learning, 14(2), 85-104. https://doi.org/10.3991/ijet.v14i02.82 $\underline{88}$

[20] Kuh, G., O'Donnell, K., \& Schneider, C. G. (2017). HIPs at ten. Change: The Magazine of Higher Learning, 49(5), 8-16. https://doi.org/10.1080/00091383.2017.1366805

[21] Kuh, G. D., Gambino, L. M., Ludvik, M. B., \& O'Donnell, K. (2018). Accentuating Dispositional Learning from HIPs Using ePortfolio. Assessment Update, 30(3), 8-9. https://doi. org/10.1002/au.30136

[22] Lin, Q. (2008). Preservice teachers' learning experiences of constructing e-portfolios online. The Internet and Higher Education, 11(3-4), 194-200. https://doi.org/10.1016/j.ihed uc. 2008.07 .002

[23] Marin, C., \& Rodriguez, S. (2012). Virtual Portfolio: A Strategy for Learning Assessment in a Graduated Virtual Program Results of a Pilot Study. International Journal of Emerging Technologies in Learning (iJET), 7(4), 48-51. https://doi.org/10.3991/ijet.v7i4.2301

[24] Penny, C., \& Kinslow, J. (2006). Faculty perceptions of electronic portfolios in a teacher education program. Contemporary Issues in Technology and Teacher Education, 6(4), 418435. https://www.citejournal.org/volume-6/issue-4-06/general/faculty-perceptions-of-elect ronic-portfolios-in-a-teacher-education-program https://doi.org/10.33915/etd.3024

[25] Ryan, R. M., \& Deci, E. L. (2000). Self-determination theory and the facilitation of intrinsic motivation, social development, and well-being. American psychologist, 55(1), https:// doi.org/10.1037/0003-066X.55.1.68

[26] Ryan, R. M., \& Deci, E. L. (2017). Self-determination theory: Basic psychological needs in motivation, development, and wellness. New York: Guilford Publishing. https://doi.org/ $10.7202 / 1041847 \mathrm{ar}$

[27] Samardzija, A. C., \& Balaban, I. (2014). From classroom to career development planning: Eportfolio use examples. International Journal of Emerging Technologies in Learning (iJET), 9(6), 26-31. https://doi.org/10.3991/ijet.v9i6.4027

[28] Strudler, N., \& Wetzel, K. (1999). Lessons from exemplary colleges of education: Factors affecting technology integration in preservice programs. Educational Technology Research and Development, 47(4), 63-81. https://doi.org/10.1007/BF02299598

[29] Swan, G. (2009). Examining barriers in faculty adoption of an e-portfolio system. Australasian Journal of Educational Technology, 25(5), 627-644. https://doi.org/10.14742/ajet.111 $\underline{2}$ 
[30] Wall, K., Higgins, S., Miller, J., \& Packard, N. (2006). Developing digital portfolios: Investigating how digital portfolios can facilitate pupil talk about learning. Technology, Pedagogy and Education, 15(3), 261-273. https://doi.org/10.1080/14759390600923535

[31] Watson, C. E., Kuh, G. D., Rhodes, T., Light, T. P., \& Chen, H. L. (2016). ePortfolios-The eleventh high impact practice. International ePortfolio Journal, 6(2), 65-69. http://www. theijep.com/pdf/IJEP254.pdf

[32] Wetcho, S., \& Na-Songkhla, J. (2019). The Different Roles of Help-Seeking Personalities in Social Support Group Activity on E-Portfolio for Career Development. International Journal of Emerging Technologies in Learning, 14(2), 124-138. https://doi.org/10.3991/ij et.v14i02.8718

[33] Wilhelm, L., Puckett, K., Beisser, S., Wishart, W., Merideth, E., \& Sivakumaran, T. (2006). Lessons learned from the implementation of electronic portfolios at three universities. TechTrends, 50(4), 62-71. https://doi.org/10.1007/s11528-006-0062-9

[34] Woodyard, J. C. (2016). Autonomy Supportive Instruction as it relates to Students' Motivational Beliefs on an ePortfolio Project: The Moderating Role of Culturally Based Learning Preferences (Doctoral dissertation, Virginia Tech).

\section{$7 \quad$ Authors}

Monika Ciesielkiewicz, Ph.D., Associate Professor, School of Education, Department of Applied Didactics; Villanueva-Complutense University of Madrid, Spain. Address: Villanueva-Universidad Complutense Madrid. Costa Brava 2, 28034. Madrid, Spain. Email: mciesielkiewicz@villanueva.edu

William Wisser, Ph.D., Director of Teaching and Learning Lab and Lecturer in Education; Harvard Graduate School of Education; Harvard University. Address: Harvard Graduate School of Education (HGSE). Appian Way, Cambridge, MA 02138, USA. Email: wiliam wisser@gse.harvard.edu

Diane Rozells, Ph.D., Assistant Professor, Graduate School of TESOL; Sookmyung Women's University. Address: Sookmyung Women's University, Department of TESOL. Sunheon Building 610. Cheongpa-ro 47-Gil 100, Yongsan-Gu. Seoul 140727, South Korea. Email: dianerozells@,sookmyung.ac.kr

Article submitted 2019-06-17. Resubmitted 2019-07-26. Final acceptance 2019-07-27. Final version published as submitted by the authors. 